\title{
ANALISIS TEGANGAN PADA TEROWONGAN BAWAH TANAH DENGAN METODE ELEMEN HINGGA
}

\author{
Yessy $^{1}$ dan Leo Tedianto ${ }^{2}$ \\ ${ }^{1}$ Program Studi Sarjana Teknik Sipil, Universitas Tarumanagara, Jl. Letjen S. Parman No.1 Jakarta \\ Yessy.325160057@stu.untar.ac.id \\ ${ }^{2}$ Program Studi Sarjana Teknik Sipil, Universitas Tarumanagara, Jl. Letjen S. Parman No.1 Jakarta \\ leotedi@ft.untar.ac.id
}

Masuk:28-06-2020, revisi: 11-07-2020, diterima untuk diterbitkan: 04-08-2020

\begin{abstract}
Construction of tunneling in Indonesia is a new thing to be implemented, especially in the capital city of Jakarta, which has land issues for surface transportation. In the construction stage of tunnels, the problem of deformation and stress to the surface of the excavation needs to be considered carefully. Therefore, the purpose of this paper is to analyze the stresses and deformations that occur in underground tunnels during the construction stage using the finite element method. Modeling is done in full 3 dimensions using a finite element based MIDAS GTS NX program. The results of the study showed that the increase in construction stage, the value of deformation that occurs in development will increase. It also occurs in stress, the more construction phases increase the greater the stress value around $0.4 \%-11 \%$. Shield release has an effect on increasing the stress, causing the stress to increase even greater up to 11\%. This study uses a hybrid mesher element to model the soil and tunnel layers. From this modeling is expected to be the beginning of complex and good tunnel modeling in the future.
\end{abstract}

Keywords: tunnel; stress; deformation; construction stage; finite element method

\begin{abstract}
ABSTRAK
Pelaksanaan konstruksi terowongan di Indonesia adalah hal yang baru diterapkan, khususnya di daerah Ibukota Jakarta yang memiliki permasalahan lahan untuk transportasi di permukaan tanah. Dalam pelaksanaan konstruksi terowongan, permasalahan tentang deformasi dan tegangan terhadap permukaan galian perlu diperhatikan dengan seksama. Untuk itu, tujuan dari penelitian ini difokuskan untuk menganalisis tegangan dan deformasi yang terjadi pada terowongan bawah tanah saat masa konstruksi berlangsung dengan menggunakan metode elemen hingga. Pemodelan dilakukan full 3-dimensi menggunakan program MIDAS GTS NX yang berbasis elemen hingga. Hasil penelitian menunjukan bahwa semakin bertambahnya tahapan konstruksi maka nilai deformasi yang terjadi pada terowongan akan semakin meningkat. Hal tersebut juga terjadi pada tegangan, semakin bertambahnya tahapan konstruksi maka nilai tegangan yang terjadi semakin besar sekitar $0.4 \%-11 \%$. Pelepasan shield berpengaruh pada meningkatnya nilai tegangan, menyebabkan nilai tegangan melonjak semakin besar $11 \%$ dari tahapan sebelumnya. Penelitian ini, menggunakan elemen hybrid mesher untuk memodelkan lapisan tanah dan terowongan. Dari pemodelan ini diharapkan menjadi awal dari pemodelan terowongan yang kompleks dan baik di masa mendatang.
\end{abstract}

Kata kunci: terowongan; tegangan; deformasi; masa konstruksi; metode elemen hingga

\section{PENDAHULUAN}

Meningkatnya pembangunan Infrastruktur di Indonesia membutuhkan lebih banyak lahan. Karena itu Indonesia menjadikan jalur bawah tanah sebagai salah satu jalur pembangunan stasiun kereta dan jalur kereta listrik. Pembangunan terowongan bawah tanah sebagai jalur transportasi di daerah urban merupakan hal yang baru di Indonesia. Terowongan pertama di Indonesia dibangun di kota Jakarta untuk melengkapi serta mendukung sarana transportasi MRT (Mass Rapid Transit) Jakarta.

MRT dibangun dengan dua jalur, yaitu jalur layang dan jalur bawah tanah. Stasiun yang terletak di jalur layang dimulai dari stasiun Lebak Bulus sampai stasiun Sisingamangaraja. Stasiun yang terletak di Jalur bawah tanah dimulai dari stasiun Senayan sampai stasiun Bundaran HI.

Pembangunan terowongan jalur bawah tanah kereta MRT Jakarta menggunakan TBM (Tunnel Boring Machine) jenis Earth Pressure Balance (EPB) buatan perusahaan dari Jepang, Japan Tunnel System Corporation (JTSC). 
Tunnel boring machine yang memiliki fungsi untuk mengebor tanah serta memasang segmen beton pada waktu yang bersamaan dan segmen beton ini yang akan membentuk dan menahan tekanan dari luar terowongan. (Jakarta, 2017)

Pembangunan terowongan terletak di bawah permukaan tanah menyebabkan banyak hal yang tidak bisa diprediksi. Perhitungan secara analitis biasanya sulit dilakukan dan untuk itu diperlukan program komputer. Banyak program komputer yang digunakan untuk menganalisis terowongan bawah tanah, diantaranya adalah PLAXIS, ABAQUS, dan MIDAS GTS NX. Program komputer tersebut menggunakan metode elemen hingga dalam menyelesaikan masalahnya. Pada penelitian ini, penulis bermaksud untuk menganalisis tegangan dan displacement yang terjadi pada terowongan selama masa konstruksi menggunakan program komputer MIDAS GTS NX.

Dalam pemodelannya dilakukan dengan pendekatan tiga dimensi sehingga diharapkan hasil yang diperoleh lebih akurat. Penelitian ini diharapkan akan memberikan kontribusi terhadap perkembangan teknologi terowongan di Indonesia.

Rumusan masalah yang akan dibahas dalam penelitian ini adalah bagaimana tegangan dan displacement yang terjadi pada terowongan pada masa konstruksi serta bagaimana pemodelan terowongan bawah tanah pada MIDAS GTS NX.

Tujuan dari penelitian ini adalah untuk mengetahui tegangan dan displacement yang terjadi pada terowongan pada masa konstruksi.

\section{Batasan masalah}

Agar penelitian ini tidak terlalu melebar, diperlukan pembatasan masalah:

- Profil geologis yang akan dimodelkan merupakan salah satu profil lapisan tanah pada sebuah proyek konstruksi terowongan bor MRT Jakarta CP 104, yang berlokasi pada Jl. Jend. Sudirman, Jakarta Selatan.

- Kasus yang akan dianalisis:

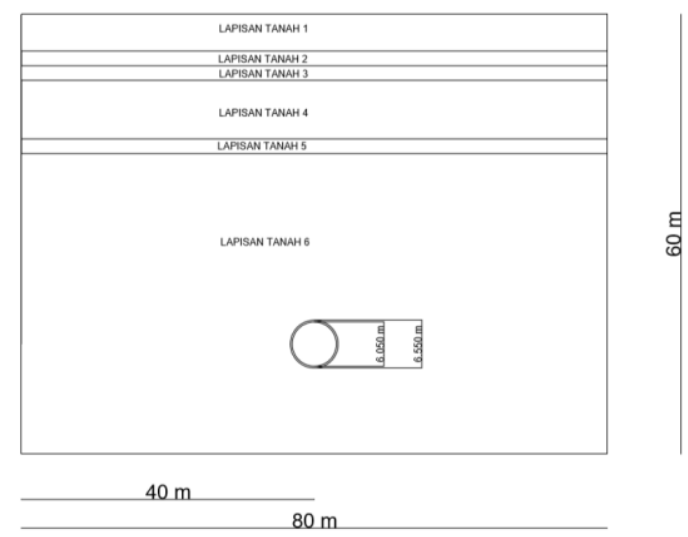

Gambar 1. Pemodelan dua dimensi terowongan bawah tanah

Gambar 1 menunjukkan bahwa lapisan tanah terdiri dari 6 jenis tanah yang berbeda-beda dan terowongan terletak pada lapisan tanah ke 6 yang diasumsikan semuanya seragam.

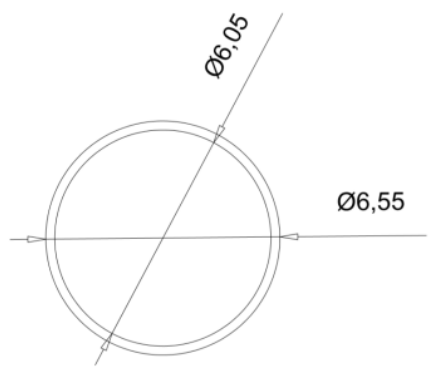

Gambar 2. Dimensi terowongan 
Gambar 2 menunjukkan dimensi terowongan luar dan terowongan dalam. Terowongan dalam memiliki diameter 6,05 $\mathrm{m}$ dan terowongan luar memiliki diameter 6,55 m. sehingga tebal dari segmen beton adalah 0,25 m

- Pembebanan berdasarkan SNI 8460-2017 Persyaratan Perancangan Geoteknik.

- Beban dinamik berupa beban gempa dan beban lalu lintas tidak diperhitungkan dalam analisis.

- Metode pelaksanaan konstruksi dilakukan berbeda dari meode pelaksanaan konstruksi pada MRT.

- Pemodelan dilakukan tanpa muka air tanah.

- Analisis struktur terowongan diasumsikan tanpa tulangan.

- Model perilaku tanah menggunakan Mohr Coulomb.

- Analisis dilakukan dengan program komputer MIDAS GTS NX

\section{METODE PENELITIAN}

Beberapa hal yang dibutuhkan penulis untuk dijadikan data input pada program MIDAS GTS NX, antara lain:

\section{Parameter tanah}

Tabel 1. Parameter tanah

\begin{tabular}{|c|c|c|c|c|c|c|c|}
\hline $\begin{array}{l}\text { Parameter } \\
\text { Tanah }\end{array}$ & Satuan & Lapisan 1 & Lapisan 2 & Lapisan 3 & Lapisan 4 & Lapisan 5 & Lapisan 6 \\
\hline Jenis Tanah & - & $\begin{array}{l}\text { Silty } \\
\text { (soft) }\end{array}$ & $\begin{array}{l}\text { Silty clay } \\
\text { (medium) }\end{array}$ & $\begin{array}{l}\text { Silty sand } \\
\text { (very stiff) }\end{array}$ & $\begin{array}{l}\text { Clay silt } \\
\text { (very hard) }\end{array}$ & $\begin{array}{l}\text { Sand (very } \\
\text { dense) }\end{array}$ & $\begin{array}{l}\text { Clay silt } \\
\text { (very hard) }\end{array}$ \\
\hline Tebal & $\mathrm{m}$ & 5 & 2 & 2 & 8 & 2 & 41 \\
\hline Model & - & $\begin{array}{l}\text { Mohr } \\
\text { Coulumb }\end{array}$ & $\begin{array}{l}\text { Mohr } \\
\text { Coulumb }\end{array}$ & $\begin{array}{l}\text { Mohr } \\
\text { Coulumb }\end{array}$ & $\begin{array}{l}\text { Mohr } \\
\text { Coulumb }\end{array}$ & $\begin{array}{l}\text { Mohr } \\
\text { Coulumb }\end{array}$ & $\begin{array}{l}\text { Mohr } \\
\text { Coulumb }\end{array}$ \\
\hline $\begin{array}{l}\text { Tipe perilaku } \\
\text { material }\end{array}$ & - & Drained & Drained & Drained & Drained & Drained & Drained \\
\hline N-SPT & - & 5 & 15 & 25 & 45 & 50 & 45 \\
\hline$\gamma_{\text {sat }}$ & $\mathrm{kN} / \mathrm{m}^{3}$ & 16 & 16 & 18 & 18 & 21,5 & 18 \\
\hline$\gamma_{\text {unsat }}$ & $\mathrm{kN} / \mathrm{m}^{3}$ & 16 & 16 & 18 & 18 & 18,5 & 18 \\
\hline $\begin{array}{l}\text { Modulus } \\
\text { Young (E) }\end{array}$ & $\mathrm{kN} / \mathrm{m}^{2}$ & 5850 & 17550 & 29250 & 52650 & 31502 & 52650 \\
\hline $\begin{array}{l}\text { Kuat geser } \\
\text { undrained } \\
\left(\mathrm{C}_{\mathrm{u}}\right)\end{array}$ & $\mathrm{kN} / \mathrm{m}^{2}$ & 29,25 & 87,75 & 146,25 & 263,25 & 0 & 263,25 \\
\hline $\begin{array}{l}\text { Rasio } \\
\text { Poisson's (v) }\end{array}$ & - & 0,4 & 0,45 & 0,35 & 0,35 & 0,35 & 0,35 \\
\hline Kohesi $\left(\mathrm{C}_{\mathrm{ref}}\right)$ & $\mathrm{kN} / \mathrm{m}^{2}$ & 5 & 10 & 15 & 30 & 0 & 30 \\
\hline $\begin{array}{l}\text { Sudut gesek } \\
\text { dalam }(\varphi)\end{array}$ & o & 10 & 15 & 32 & 34 & 37 & 34 \\
\hline $\begin{array}{l}\text { Sudut } \\
\text { dilatansi }(\psi)\end{array}$ & o & 0 & 0 & 0 & 0 & 0 & 0 \\
\hline
\end{tabular}


Dari tabel 1 data yang akan digunakan adalah sudut gesek dalam, kohesi, rasio poisson, modulus young dan berat jenis. Dari data diatas semuanya akan dimasukan dalam program MIDAS GTS NX .

\section{Pembebanan}

Pembebanan yang terjadi pada terowongan diasumsikan berupa berat sendiri tanah dan juga tekanan dari alat TBM (tabel 2). Terdapat beberapa beban lainnya yaitu Face pressure (TBM head exavation side) (HP), Upper shield pressure (S),Upper segment pressure (E), Jack forces (segment) (J) (NX, 2014).

Tabel 2. Pressure load

\begin{tabular}{|c|c|c|c|c|c|}
\hline \multirow{2}{*}{$\begin{array}{l}\text { Tahapan } \\
\text { konstruksi }\end{array}$} & \multicolumn{4}{|c|}{ Loading } & \multirow{2}{*}{$\begin{array}{c}\begin{array}{c}\text { Remove } \\
\text { loading }\end{array} \\
\text { jack } \\
\text { forces } \\
\text { (segment) }\end{array}$} \\
\hline & $\begin{array}{l}\text { Face pressure } \\
(\mathrm{TBM} \text { head } \\
\text { exavation side) }\end{array}$ & $\begin{array}{c}\text { upper shield } \\
\text { pressure }\end{array}$ & $\begin{array}{c}\text { upper } \\
\text { segment } \\
\text { pressure }\end{array}$ & $\begin{array}{l}\text { jack forces } \\
\text { (segment) }\end{array}$ & \\
\hline 1 & - & - & - & - & - \\
\hline 2 & $\begin{array}{l}\text { HP1(internal } 3 \\
\text { depan muka) }\end{array}$ & $\begin{array}{c}\text { S1 (eksternal } \\
1,2)\end{array}$ & - & - & - \\
\hline 3 & $\begin{array}{l}\text { HP2 (internal } 5 \\
\text { depan muka) }\end{array}$ & $\begin{array}{c}\text { S2 (eksternal } \\
3,4)\end{array}$ & - & - & - \\
\hline 4 & $\begin{array}{l}\text { HP3(internal } 7 \\
\text { depan muka) }\end{array}$ & $\begin{array}{l}\text { S3 (eksternal } \\
5,6)\end{array}$ & - & - & - \\
\hline 5 & $\begin{array}{l}\text { HP4(internal } 9 \\
\text { depan muka) }\end{array}$ & $\begin{array}{c}\text { S4 (eksternal } \\
7,8)\end{array}$ & - & - & - \\
\hline 6 & HP5(internal 11) & $\begin{array}{c}\text { S5 (eksternal } \\
9,10)\end{array}$ & - & - & - \\
\hline 7 & HP6(internal 13) & $\begin{array}{c}\text { S6 (eksternal } \\
11,12)\end{array}$ & - & - & - \\
\hline 8 & HP7(internal 15) & $\begin{array}{c}\text { S7 (eksternal } \\
13,14)\end{array}$ & - & $\begin{array}{c}\mathrm{J} 1 \text { (external } \\
2)\end{array}$ & - \\
\hline 9 & HP8(internal 17) & $\begin{array}{c}\text { S8 (eksternal } \\
15,16)\end{array}$ & $\begin{array}{c}\text { E1 (eksternal } \\
1,2)\end{array}$ & $\begin{array}{c}\mathrm{J} 2 \text { (external } \\
4)\end{array}$ & $\begin{array}{l}\mathrm{J} 1 \text { (extern } \\
\text { al 2) }\end{array}$ \\
\hline 10 & HP9(internal 19) & $\begin{array}{c}\text { S9 (eksternal } \\
17,18)\end{array}$ & $\begin{array}{c}\text { E2 (eksternal } \\
3,4)\end{array}$ & $\begin{array}{c}\text { J3(external } \\
6)\end{array}$ & $\begin{array}{l}\text { J2(extern } \\
\text { al } 4)\end{array}$ \\
\hline 11 & HP10(internal 21) & $\begin{array}{c}\text { S10 (eksternal } \\
19,20)\end{array}$ & $\begin{array}{c}\text { E3 (eksternal } \\
5,6)\end{array}$ & $\begin{array}{c}\text { J4(external } \\
8)\end{array}$ & $\begin{array}{l}\text { J3(extern } \\
\text { al 6) }\end{array}$ \\
\hline 12 & HP11(internal 23) & $\begin{array}{c}\text { S11 (eksternal } \\
21,22)\end{array}$ & $\begin{array}{c}\text { E4 (eksternal } \\
7,8)\end{array}$ & $\begin{array}{c}\text { J5(external } \\
10)\end{array}$ & $\begin{array}{l}\text { J4(extern } \\
\text { al 8) }\end{array}$ \\
\hline 13 & HP12(internal 25) & $\begin{array}{c}\text { S12 (eksternal } \\
23,24)\end{array}$ & $\begin{array}{c}\text { E5 (eksternal } \\
9,10)\end{array}$ & $\begin{array}{c}\text { J6(external } \\
12)\end{array}$ & $\begin{array}{l}\text { J5(extern } \\
\text { al 10) }\end{array}$ \\
\hline 14 & HP13(internal 27) & $\begin{array}{c}\text { S13 (eksternal } \\
25,26)\end{array}$ & $\begin{array}{c}\text { E6 (eksternal } \\
11,12)\end{array}$ & $\begin{array}{c}\mathrm{J} 7(\text { external } \\
14)\end{array}$ & $\begin{array}{l}\text { J6(extern } \\
\text { al 12) }\end{array}$ \\
\hline 15 & HP14(internal 29) & $\begin{array}{c}\text { S14 (eksternal } \\
27,28)\end{array}$ & $\begin{array}{c}\text { E7 (eksternal } \\
13,14)\end{array}$ & $\begin{array}{c}\text { J8(external } \\
16)\end{array}$ & $\begin{array}{l}\text { J7(extern } \\
\text { al 14) }\end{array}$ \\
\hline 16 & - & $\begin{array}{c}\text { S15(eksternal } \\
29,30)\end{array}$ & $\begin{array}{c}\text { E8 (eksternal } \\
15,16)\end{array}$ & $\begin{array}{c}\text { J9(external } \\
18)\end{array}$ & $\begin{array}{l}\text { J8(extern } \\
\text { al 16) }\end{array}$ \\
\hline
\end{tabular}


Lanjutan Tabel 2. Pressure load

\begin{tabular}{|c|c|c|c|c|c|}
\hline 17 & - & - & $\begin{array}{c}\text { E9 (eksternal } \\
17,18)\end{array}$ & $\begin{array}{l}\mathrm{J} 10 \text { (external } \\
20 \text { ) }\end{array}$ & $\begin{array}{l}\text { J9(extern } \\
\text { al 18) }\end{array}$ \\
\hline 18 & - & - & $\begin{array}{c}\text { E10 } \\
\text { (eksternal } \\
19,20)\end{array}$ & $\begin{array}{l}\text { J11(external } \\
22)\end{array}$ & $\begin{array}{c}\text { J10(exter } \\
\text { nal 20) }\end{array}$ \\
\hline 19 & - & - & $\begin{array}{c}\text { E11 } \\
\text { (eksternal } \\
21,22)\end{array}$ & $\begin{array}{l}\text { J12(external } \\
24)\end{array}$ & $\begin{array}{c}\text { J11(exter } \\
\text { nal 22) }\end{array}$ \\
\hline 20 & - & - & $\begin{array}{c}\text { E12 } \\
\text { (eksternal } \\
23,24)\end{array}$ & $\begin{array}{l}\text { J13(external } \\
26)\end{array}$ & $\begin{array}{c}\text { J12(exter } \\
\text { nal 24) }\end{array}$ \\
\hline 21 & - & - & $\begin{array}{c}\mathrm{E} 13 \\
\text { (eksternal } \\
25,26)\end{array}$ & $\begin{array}{c}\text { J14(external } \\
28)\end{array}$ & $\begin{array}{c}\text { J13(exter } \\
\text { nal 26) }\end{array}$ \\
\hline 22 & - & - & $\begin{array}{c}\text { E14 } \\
\text { (eksternal } \\
27,28)\end{array}$ & $\begin{array}{c}\text { J15(external } \\
30)\end{array}$ & $\begin{array}{c}\text { J14(exter } \\
\text { nal 28) }\end{array}$ \\
\hline 23 & - & - & $\begin{array}{c}\text { E15(eksternal } \\
29,30)\end{array}$ & - & - \\
\hline
\end{tabular}

\section{HASIL DAN PEMBAHASAN}

Banyak tahapan yang perlu diperhatikan dalam melakukan pekerjaan pembuatan terowongan agar mendapatkan hasil seperti yang telah direncanakan. Memodelkan konstruksi merupakan tahapan yang penting agar perencana dapat melakukan kajian awal dan menjadikan hasil dari pemodelan tersebut menjadi acuan bagi pekerjaan engineer secara riil di lapangan (Departemen Pekerjaan Umum, 2008). Pada bab ini, akan dijelaskan pemodelan yang dilakukan secara tiga dimensi pada program komputer MIDAS GTS NX untuk mendapatkan hasil yang diharapkan mendekati keadaan ril di lapangan. Jumlah pemodelan memiliki 28 urutan pekerjaan. Beberapa data yang diperlukan dalam pemodelan ini yaitu Modulus elastisitas tanah (E), Poisson ratio (v), berat jenis tanah, nilai kohesi tanah, sudut geser tanah, dan beberapa data lain yang akan menjadi acuan dalam pemodelan.

Dalam bab ini juga akan dilakukan analisis hasil dari pemodelan yang telah dijalankan pada program komputer MIDAS GTS NX. Analisis berupa data tegangan maksimum dan deformasi maksimum yang terjadi.

\section{Hasil displacement}
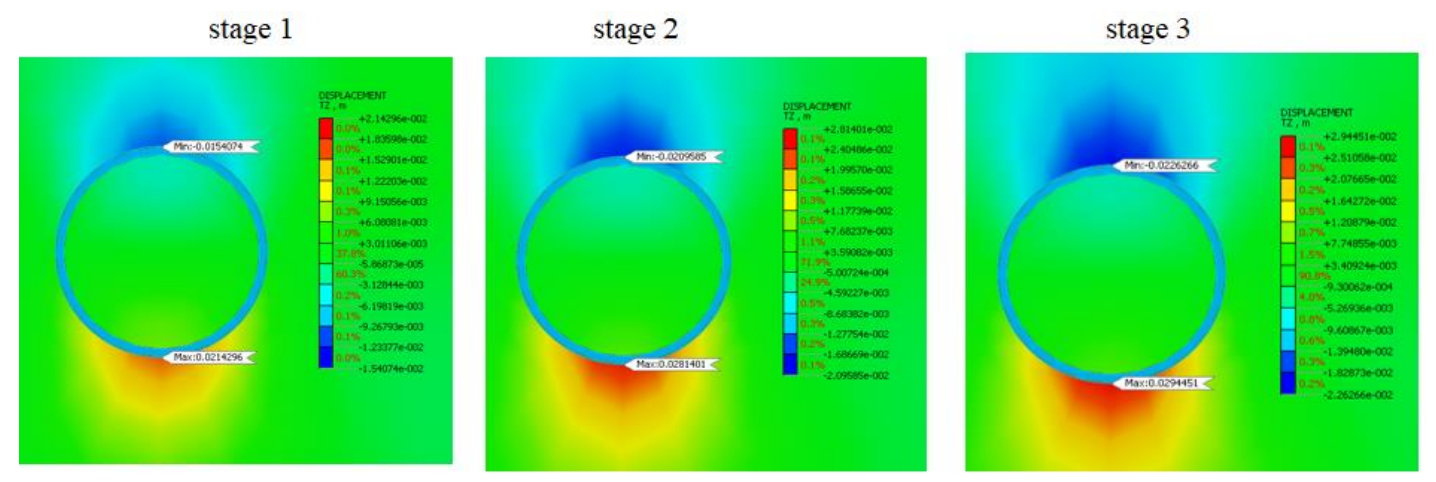

Gambar 3. Hasil displacement pada tahap 1-3

Displacement yang ditinjau pada analisis ini adalah searah z. Arah z merupakan arah deformasi vertikal. Berdasarkan hasil analisis, nilai displacement yang terjadi pada terowongan bagian atas lebih kecil dibandingkan dengan nilai displacement terowongan bagian bawah. Pada tahap 1 yang terlihat pada gambar 3, nilai displacement 
maksimum pada terowongan bagian atas adalah (-)0.015m dan pada bagian bawah terowongan adalah $(+) 0.021$. nilai (-) menunjukan posisi displacement kearah bawah dan nilai (+) menunjukan posisi displacement kearah atas. Warna merah dan warna biru pada program komputer menunjukan nilai displacement yang terjadi. Jika semakin menuju ke warna merah maka displacement semakin besar searah(+). Jika semakin biru maka displacement semakin besar searah (-). Semakin bertambahnya tahapan konstruksi, maka semakin besar nilai displacement yang terjadi diposisi atas maupun bawah terowongan. Maka seakan-akan bentuk terowongan semakin 'terjepit'. Deformasi atas terowongan semakin menekan kebawah dan deformasi bawah terowongan semakin menekan keatas. Hal ini terjadi seiring bertambahnya proses penggalian. Tetapi pada saat tahapan penggalian sudah mulai selesai, nilai displacement atas dan bawah terowongan menunjukan kecenderungan nilai displacement yang sama besar antara atas dan bawah terowongan.

Deformasi pada dinding terowongan dibatasi hanya $6 \%$ dari diameter terowongan. (Liu, Small, \& Carter, 2008) Nilai deformasi berdasarkan $6 \%$ dari dinding terowongan sebesar $=0,3633 \mathrm{~m}$ atau 363,3 mm. Jika dibandingkan dengan deformasi maksimum yang terjadi pada kedalaman $45 \mathrm{~m}$ adalah sebesar $0,03 \mathrm{~m}$ atau $30 \mathrm{~mm}$ maka pada saat tahapan konstruksi berlangsung terowongan tergolong aman berdasarkan batas diatas.

Tabel 3. Hasil displacement maksimum arah z

\begin{tabular}{|c|c|c|c|}
\hline $\begin{array}{l}\text { Tahapan } \\
\text { Konstruksi }\end{array}$ & $\begin{array}{l}\text { Displacement } \\
\text { Arah z (m) }\end{array}$ & $\begin{array}{l}\text { Tahapan } \\
\text { Konstruksi }\end{array}$ & $\begin{array}{l}\text { Displacement } \\
\text { Arah z }(\mathrm{m})\end{array}$ \\
\hline tahap awal & 0,00000000 & stage 15 & 0,03003929 \\
\hline stage 1 & 0,02142956 & stage 16 & 0,03000048 \\
\hline stage 2 & 0,02814010 & stage 17 & 0,02993661 \\
\hline stage 3 & 0,02944507 & stage 18 & 0,02982920 \\
\hline stage 4 & 0,02944507 & stage 19 & 0,02966448 \\
\hline stage 5 & 0,02953621 & stage 20 & 0,03009345 \\
\hline stage 6 & 0,02951263 & stage 21 & 0,03034703 \\
\hline stage 7 & 0,03025756 & stage 22 & 0,03072254 \\
\hline stage 8 & 0,03001398 & stage 23 & 0,03071477 \\
\hline stage 9 & 0,03001255 & stage 24 & 0,03070011 \\
\hline stage 10 & 0,03021613 & stage 25 & 0,03067519 \\
\hline stage 11 & 0,03017488 & stage 26 & 0,03063612 \\
\hline stage 12 & 0,03012821 & stage 27 & 0,03057940 \\
\hline stage 13 & 0,02995985 & stage 28 & 0,03050211 \\
\hline
\end{tabular}

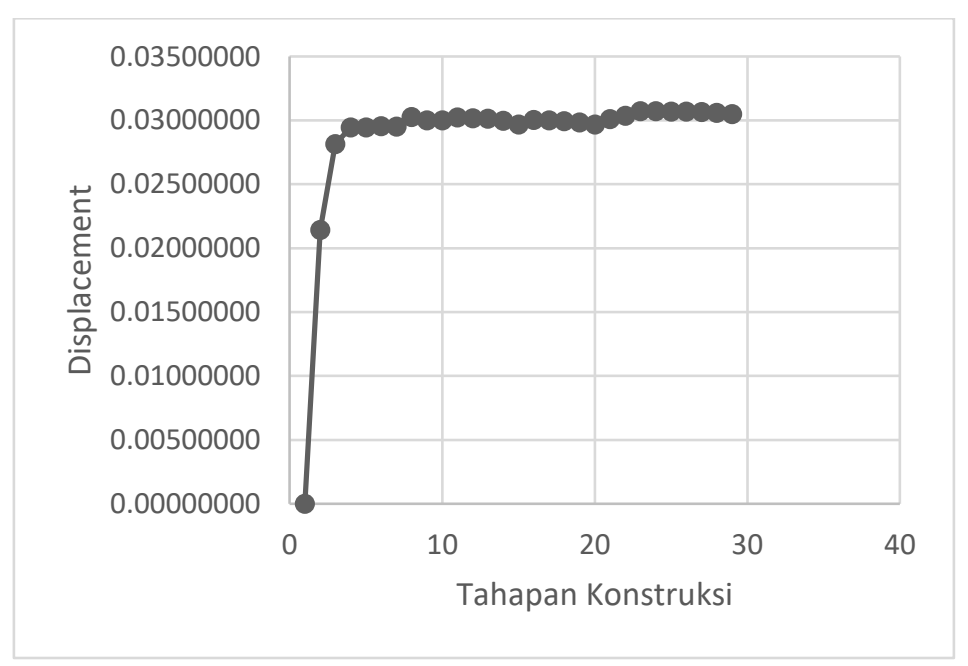

Gambar 4. Grafik displacement maksimum arah z 
Proses penggalian selesai pada tahap ke 15. Pada gambar 4 dan tabel 3 dapat dilihat bahwa semakin bertambahnya tahapan konstruksi maka semakin besar displacement yang terjadi. Hasil displacement terbesar pada terowongan arah vertikal adalah $0,0307 \mathrm{~m}$ yang terjadi pada tahap 22 dan hasil displacement terkecil terjadi pada tahap 1 yaitu $0,021 \mathrm{~m}$ atau $21 \mathrm{~mm}$.

\section{Hasil tegangan}
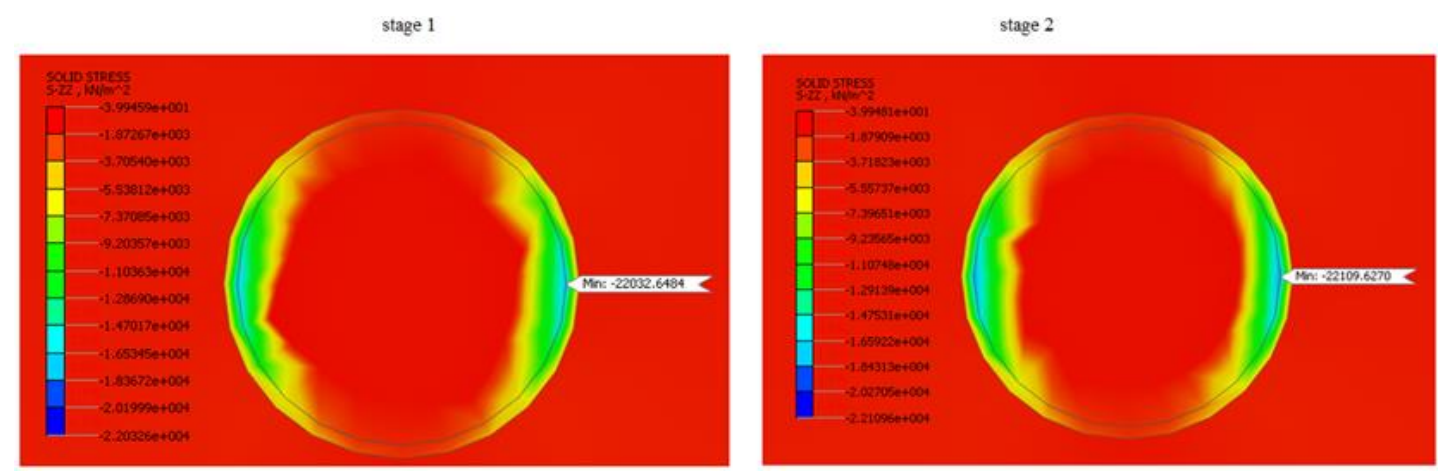

Gambar 5. Hasil tegangan pada tahap 1-2

Hasil tegangan pada permukaan galian terbagi menjadi 3 bagian, yaitu tegangan arah xx, tegangan arah yy dan tegangan arah zz. Pada penelitian ini, hanya tegangan arah zz yang akan dianalisis. Tegangan yang terjadi ditampilkan dalam bentuk gambar 5. Perjanjian tanda pada midas (-) menunjukan terjadinya tegangan tekan dan (+) menunjukan terjadinya tegangan tarik. Seiring bertambahnya tahapan konstruksi, maka penggalian semakin dalam searah sumbu y. Pada tahap initial phase, tegangan yang terjadi sebesar $-18380,4785 \mathrm{Kn} / \mathrm{m} 2$. Tegangan yang terjadi pada tahapan initial phase ini diakibatkan beban tanah sendiri karena pada tahap ini belum terjadinya penggalian.

Tahapan pertama dimulai dengan penggalian sejauh $4 \mathrm{~m}$, dilanjutkan dengan tahapan kedua sejauh 8 meter dari muka penggalian dan seterusnya. Tegangan maksimum yang terjadi pada tahap 1 (sepanjang $4 \mathrm{~m}$ penggalian) adalah $-22032,6484 \mathrm{kn} / \mathrm{m} 2$. Hasil penelitian menunjukan distribusi tegangan yang terjadi berpusat pada dinding terowongan. Pada program komputer MIDAS GTS NX, besarnya tegangan digambarkan dengan warna, pembacaan tegangan dimulai dari atas ke bawah. Semakin kebawah (berwarna biru) maka semakin besar nilai tegangan yang terjadi. Pada Tahap 1, tegangan yang berwarna biru menunjukan nilai maksimum tegangan yang terjadi pada setiap tahapan penggalian. Perubahan tegangan yang terjadi dari tahapan 1-7 menunjukan semakin dalam penggalian, nilai tegangan yang terjadi semakin besar.

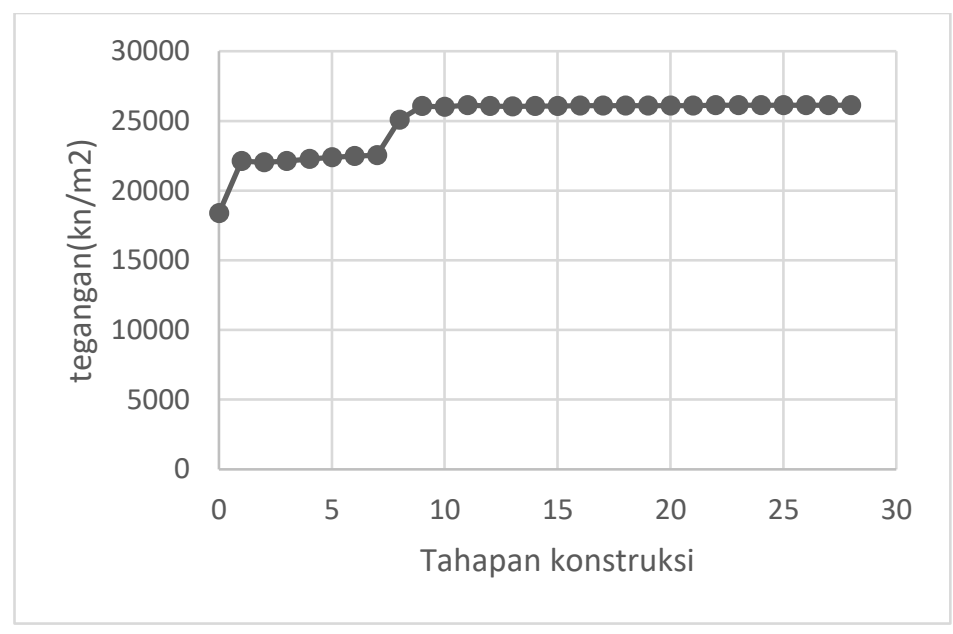

Gambar 6. Grafik tegangan maksimum arah zz

Pada gambar 6 nilai tegangan searah sumbu z cenderung naik ketika dilakukan konstruksi terowongan. Nilai tegangan yang mengalami kenaikan yang cenderung kecil menyebabkan bentuk grafik seolah-olah datar. Tetapi terdapat lonjakan kenaikan tegangan dimulai dari tahap 7 ke tahap 8-9, hal ini disebabkan karena pelepasan shield 1-2 yang dilakukan pada tahap 8 sehingga mempengaruhi kenaikan nilai tegangan pada tahap 8 . Pelepasan shield 
yang terjadi menyebabkan nilai tegangan yang terjadi menjadi lebih besar dibandingkan pada saat shield terpasang pada saat konstruksi. Peningkatan tegangan yang terjadi setelah penggalian selesai menjadi lebih kecil sekitar 50\%-100\% presentasenya dibandingkan pada saat proses penggalian terjadi. Pada tahapan 22-28, hanya terjadi pemasangan grouting sehingga nilai tegangan yang terjadi pada tahap itu cenderung menjadi stabil atau sama.

Tabel 4. Hasil tegangan maksimum arah zz

\begin{tabular}{|c|c|c|c|}
\hline $\begin{array}{l}\text { Tahapan } \\
\text { konstruksi }\end{array}$ & Tegangan & $\begin{array}{l}\text { Tahapan } \\
\text { konstruksi }\end{array}$ & Tegangan \\
\hline tahap awal & $-18380,479$ & stage 16 & $-26084,748$ \\
\hline stage 1 & $-22032,648$ & stage 17 & $-26091,221$ \\
\hline stage 2 & $-22109,627$ & stage 18 & $-26096,941$ \\
\hline stage 3 & $-22110,648$ & stage 19 & $-26101,057$ \\
\hline stage 4 & $-22277,256$ & stage 20 & $-26104,096$ \\
\hline stage 5 & $-22378,865$ & stage 21 & $-26106,645$ \\
\hline stage 6 & $-22483,313$ & stage 22 & $-26108,127$ \\
\hline stage 7 & $-22548,576$ & stage 23 & $-26108,688$ \\
\hline stage 8 & $-25063,281$ & stage 24 & $-26109,031$ \\
\hline stage 9 & $-26071,318$ & stage 25 & $-26109,219$ \\
\hline stage 10 & $-25996,414$ & stage 26 & $-26109,301$ \\
\hline stage 11 & $-26131,881$ & stage 27 & $-26109,32$ \\
\hline stage 12 & $-26055,658$ & stage 28 & $-26109,311$ \\
\hline stage 13 & $-26046,246$ & & \\
\hline stage 14 & $-26065,803$ & & \\
\hline stage 15 & $-26076,805$ & & \\
\hline
\end{tabular}

Tabel 4 menunjukkan nilai hasil tegangan maksimum arah zz. Tegangan pada tabel 4 dalam Kn/m2.

\section{KESIMPULAN DAN SARAN}

\section{Kesimpulan}

Berdasarkan hasil analisis FEM dengan bantuan program MIDAS GTS NX maka diambil beberapa kesimpulan sebagai berikut:

1. Displacement yang terjadi pada setiap tahapan konstruksi menghasilkan nilai yang berbeda-beda. Semakin bertambahnya tahapan konstruksi, maka displacement yang terjadi semakin besar.

2. Deformasi maksimal yang diakibatkan oleh pembangunan terowongan ini cukup kecil yaitu $30 \mathrm{~mm}$ atau $0.03 \mathrm{~m}$. Secara umum terowongan diketahui mengalami penyusutan dari bentuk aslinya. Hal ini sesuai dengan ketetapan bahwa deformasi pada dinding terowongan dibatasi $6 \%$ dari diameter dinding terowongan.

3. Nilai tegangan yang terjadi pada setiap tahapan konstruksi menghasilkan nilai yang berbeda-beda. Semakin bertambahnya tahapan konstruksi, maka tegangan yang terjadi cenderung menjadi lebih besar. Terjadinya lonjakan nilai tegangan pada saat tahap ke-8 yaitu ketika shield mulai dilepas. Hal tersebut mengakibatkan nilai tegangan berubah menjadi jauh lebih besar dari tegangan tahap 1-7 setelah itu nilai tegangan cenderung konstan.

\section{Saran}

Berdasarkan proses penelitian yang telah dilakukan ditemukan beberapa masalah baru yang belum dapat terpecahkannn, oleh karena itu peneliti memberi saran untuk penelitian selanjutnya: 
1. Pemodelan terowongan akan lebih baik dan akurat jika dibagi dalam layer yang lebih banyak sehingga mempresentasikan keadaan dilapangan yang terdiri dari banyak layer dan berbeda jenis tanah.

2. Dalam menganalisis hasil displacement dan tegangan yang terjadi pada terowongan selama masa konstruksi, peneliti hanya mengambil nilai maksimum dari setiap tahapan konstruksi. Maka dari itu, diperlukan penelitian lanjutan agar dapat mengetahui perubahan nilai displacement dan tegangan yang terjadi pada posisi tertentu disetiap tahapan konstruksi.

3. Perlu diadakan penelitian lanjutan mengenai tegangan dan displacement yang terjadi pada terowongan jika ditambahkan dengan beban gempa.

4. Dalam pemodelan terowongan menggunakan program komputer MIDAS GTS NX terdapat hal-hal yang perlu diperhatikan yaitu parameter tanah, jenis elemen yang akan digunakan dan pemodelan construction stage.

\section{DAFTAR PUSTAKA}

Departemen Pekerjaan Umum. Pedoman Pengawasan Penyelenggaraan Pekerjaan Konstruksi . Jakarta Selatan: Departemen Pekerjaan Umum, 2008.

Jakarta, MRT. "Tunnel Boring Machine : Si Penggerus Tanah di Terowongan MRT Jakarta Fase 1." Info Terkini 4 juli 2017.

Liu, H.Y., J.C. Small and J.P. Carter. "Full 3D Modelling for Effects of Tunnelling on Existing Support System in Sydney Region." ScienceDirect (2008): 399-420.

NX, MIDAS GTS. User Manual. 2014. 
Analisis Tegangan pada Terowongan Bawah Tanah dengan

Yessy, et al Metode Elemen Hingga 